INVESTIGACIÓN/RESEARCH

\title{
ELEMENTOS DEL PROCESO DE COMUNICACIÓN QUE ORIENTAN EL DISCURSO DE LOS PROFESORES UNIVERSITARIOS
}

\begin{abstract}
María Guanipa-Pérez1: Universidad Rafael Belloso Chacín en Maracaibo. Venezuela maria.guanipa@.urbe.edu
\end{abstract}

\section{RESUMEN}

Esta investigación tuvo como objetivo analizar los elementos del proceso de comunicación que orientan el discurso de los profesores universitarios. Para ello se realizó un estudio de campo, carácter descriptivo; con un enfoque hermenéutico mediante la utilización de los enfoques de investigación cualitativo y cuantitativo, clasificando este estudio como un diseño no experimental-transversal. Por otra parte, se hizo una revisión bibliográfica cuyo análisis permitió conocer los actos comunicativos que se dan en el aula entre el profesor y el alumno y como este podrá interpretarlos para luego comprenderlos. Se concluye que mas de la mitad de los estudiantes, de Comunicación Social consideran que el profesor no utiliza un lenguaje explícito, no comparten con los alumnos el conocimiento del contenido programático, no comparte las experiencias de los profesores para emitir sus mensajes, no posee los recursos para emitir mensajes de diferente manera, los cálculos erróneos de los alumnos no son atendidos por los profesores, los estudiantes desconocen las intenciones del profesor durante las clases presenciales, antes de iniciar el proceso de comunicación los profesores no captan la atención del alumno, están de acuerdo que los múltiples significados del lenguaje utilizados por los profesores interfieren en la comprensión durante los encuentros pedagógicos..

PALABRAS CLAVE: Proceso de comunicación - Discurso del profesor - Encuentros pedadógicos - Relación dialógica

\footnotetext{
${ }^{1}$ Autor correspondiente:

María Guanipa-Pérez: Directora del Centro de Investigación de Humanidades y Educación CIHE.. Universidad Rafael Belloso Chacín en Maracaibo, Venezuela.

Correo: maria.guanipa@.urbe.edu
} 


\title{
ELEMENTS OF THE COMMUNICATION PROCESS TO GUIDE THE DISCOURSE OF UNIVERSITY PROFESSORS
}

\begin{abstract}
This research aimed to analyse the elements of the communication process that guide the discourse of university professors. This was a field study, descriptive; a hermeneutic approach through the use of research approaches to qualitative and quantitative, classifying this study as a not experimental-transversal design. On the other hand, became a literature review whose analysis allowed to know the communicative acts that occur in the classroom between teacher and students and like this may interpret them to then understand them. It was concluded that more than half of the students, social communications considered the teacher does not use explicit language, do not share with the students the knowledge of the programmatic content, does not share the experiences of teachers to deliver their messages, does not have the resources to deliver messages in a different way, erroneous calculations of the students are not cared for by teachersstudents are unaware of the intentions of the teacher during the face-to-face classes, before starting the process of communication teachers do not capture the attention of the student, agree that the multiple meanings of the language used by teachers interfere with understanding during teaching meetings...
\end{abstract}

KEY WORDS: Communication process - Speech teacher - Encounters pedadógicos Dialogic relationship

\section{INTRODUCCIÓN}

La relación dialógica, comprende la interacción entre dos o más sujetos capaces de utilizar el lenguaje para comunicarse y establecer una relación interpersonal. En ese sentido, los actores involucrados tratan entenderse sobre una situación determinada, de manera tal que pueda coordinar de común acuerdo su comportamiento.

De allí que el pretender un entendimiento mutuo conlleva la existencia de una acción mental segura, dentro del acto comunicativo. De manera que, la comprensión y la aceptación de un acto del lenguaje como consecuencia de la acción comunicativa en un salón de clase por ejemplo, están mediados por la confianza que pueda existir entre las partes involucradas en este caso, entre el profesor y los alumnos; quienes hacen parte de la interacción dialógica pedagógica, convirtiéndose en un acto de confianza racional mutua. Así, el mundo concreto, comprensivo del profesor es un mundo lingüísticamente interpretado por los estudiantes, donde su realidad resulta transmitida mediante expresiones significativas. Igualmente, el ejercicio de la cultura académica, como sub.-sistema, de la problemática del conocimiento entre sus protagonistas (alumnos -profesor). 
Vale decir, que la dinámica del discurso profesoral se desenvuelve en la búsqueda de las pretensiones de verdad concertada racionalmente, y sostenida por mecanismos de la confianza racional cuya supremacía, afianza y dinamiza las relaciones entre profesores - alumnos quienes buscan los espacios para realizar las discusiones sobre el conocimiento fortaleciendo el desarrollo comunicativo en la vida académica.

La misma pedagogía según Flórez (1999) como disciplina en construcción, tiene como objetivo comprender conceptos e interpretaciones sobre los procesos en la enseñanza como eventos formativos, en los cuales los individuos se habilitan como pensadores e interlocutores competentes para validar el sentido, la intencionalidad y los planes de acción entre ellos, con miras a su entendimiento y mejoramiento, no es algo que pueda adelantarse sin seriedad, o pueda dejarse a la veleidad subjetiva del profesor.

Según Habermas (1990) un proceso educador es un acto de comunicación donde se busca una relación de entendimiento siempre mediado por el acuerdo racional, de allí, la palabra del profesor presenta siempre una conducta compleja la cual no puede representarse con una definición analítica. Cada palabra posee un significado básico, pero su significado real surge de la modificación a causa de factores sociales e individuales los cuales forman un contexto situacional.

De otro modo, la comunicación sería infructuosa y conflictiva, pues se alejaría de las condiciones mínimas de argumentación y de diálogo. De igual manera, los profesores no logran comprender en toda su extensión la significación de los cambios e individualidades, siguen apegados a sus propios esquemas de trabajo. Cada docente enfatiza en la instrucción lo que a su juicio cree importante, ante esta situación, los estudiantes, reflejan una actitud de rechazo a lo presentado y lo transmitido en el discurso de su profesor como única vía de acceso al conocimiento durante las clases magistrales.

\section{METODOLOGÍA}

Reflexionando sobre lo expuesto en la introducción, anteriormente, cabe preguntarse en un nivel previo de esquema funcional:

¿Cuáles son los elementos del proceso de comunicación que orientan el discurso del profesor en su acción dialógica en la Escuela de Comunicación Social de la Universidad Rafael Belloso Chacín en Maracaibo?.

Metodológicamente nos hallamos ante la necesidad de crear unas herramientas, a modo de diagrama de flujos, que supongan un elemento básico de encuadre de la realidad circundante, de manera que se enfoquen los aspectos que interesan en la construcción formal y semántica del discurso docente.

El presente artículo, como todos los propios de las Ciencias Sociales, parte de una necesidad epistemológica inicial sustentada, en primer lugar, sobre una exhaustiva analítica de fuentes para describir el status quo de partida del objeto de nuestro 
estudio y, posteriormente, en una segunda fase, unida indeleblemente a la anterior, pasaría a basarse en un análisis textual que incluye no sólo el estado de la cuestión hasta el momento, sino nuevos contenidos y aportaciones a la investigación, de manera que holísticamente se alcance una hermenéutica plena, tratando de eludir problemas interpretativos (deductivo-culturales) y de elidir los aspectos, que por consabidos, frenarían el avance del texto so pretexto de una hipertrofiada detención en los detalles confortantes que el acervo propio del lector avezado en temas comunicativos (lector ideal), se presupone, atesora.

El proceso inductivo-deductivo, basado tanto en estudios de fuentes como de casos, así como la proyección de nuevas ideas apalancadas en los criterios canónicos anteriores, se erige como el método adecuado para poder avanzar en los conocimientos en el área de la comunicación, entendida ésta no sólo como fin (objeto de estudio) sino también como medio (vehículo para transmitir otros saberes humanísticos propios de una publicación científica del área de Humanidades).

\section{ANÁLISIS Y DISCUSIÓN}

Respecto a las disciplinas implicadas en el discurso, la filosofía de la educación tiene como uno de los cuidados fundamentales completar las insuficiencias de las ciencias y tecnologías particulares de la educación. En ese sentido, Fullat (1995) considera a la educación como "un cuestionamiento de lo que se hace y se dice en los campos educativos y pedagógicos en general" (p. 91). Esta disciplina toma dos orientaciones: (a) saber lo que se dice y (b) saber lo que se hace en el contexto cognitivo (Figura 1).

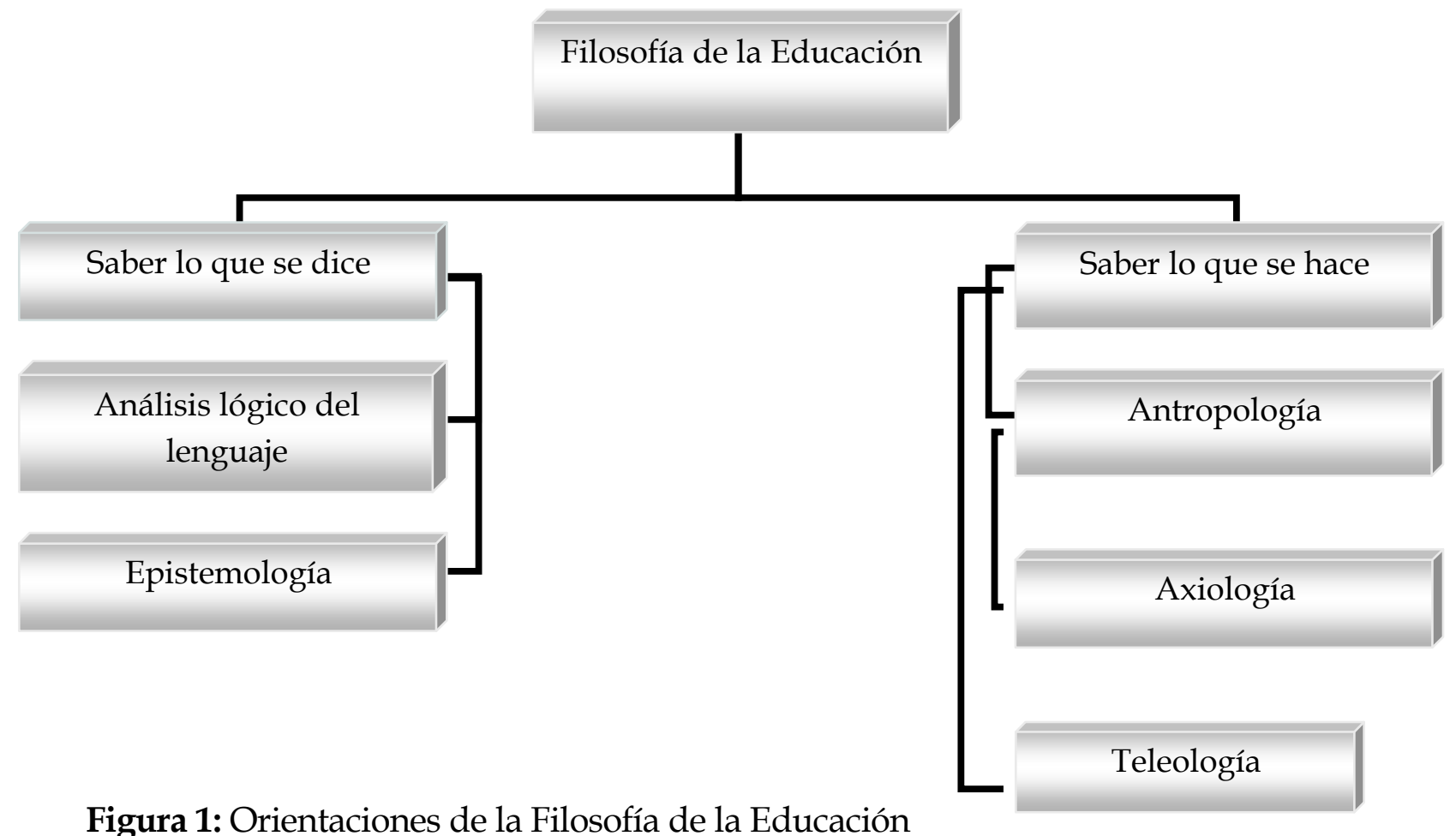

Figura 1: Orientaciones de la Filosofía de la Educación

Fuente: Fullat (1995) 
Importa señalar, la filosofía de la educación no se interesa por saber cómo educar, con qué, en qué medio, a qué sujeto psicológico, sino quién es el educando, qué es la educación y para qué se educa. En concordancia con las ideas del autor antes mencionado, Moore (citado por Fullat, 1995), refiere que:

Los filósofos de la educación, no se dedican por lo general a formular sus propias teorías de la educación, sino a analizar y clasificar los conceptos utilizados en el discurso educativo y a examinar los argumentos y justificaciones que proponen quienes formulan teorías de la educación. (p.93)

Pareciera que en educación está todo dicho, no obstante, la presente investigación centró su atención tomando como punto focal las tareas competentes a la filosofía de la educación (Figura 2).

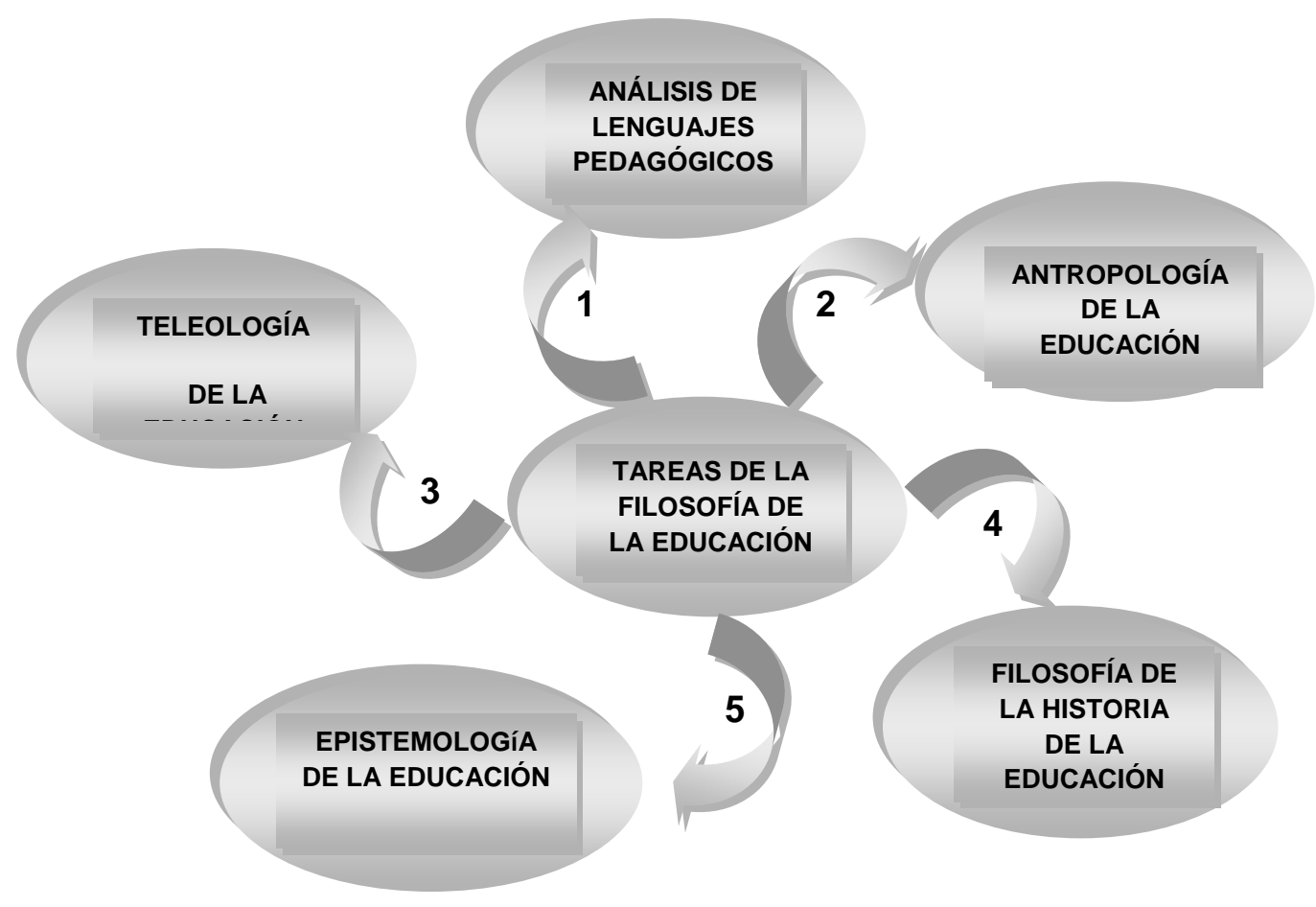

Figura 2: Tareas de la Filosofía de la Educación.

Fuente: Fullat (1995) Adoptado por Guanipa (2010)

En la actualidad, el pensamiento pedagógico según Fullat (1995) es una reflexión centrada en el lenguaje y para saber si un problema educativo tiene o no sentido conviene examinar su construcción de las proposiciones donde viene formulado y a través de las cuales se vehicula.

El proceso educador es un acto comunicacional, vale destacar el lenguaje como el elemento más importante de mediación comunicativa, en ese ámbito, la filosofía del lenguaje se dedica al estudio de los lenguajes, tanto de educadores, como de 
pedagogos (profesores) cuya palabra presenta una conducta la cual no puede representarse con una definición analítica.

Cada palabra posee un significado básico o denotativo, pero su significado real surge de las modificaciones del primero, a causa de factores sociales e individuales que forman un contexto situacional, en el cual, la triada conformada por el hombre, la cultura y la educación constituyen tres conceptos interrelacionados tan fuertemente donde uno no se entiende sin los otros dos. (Figura 3).

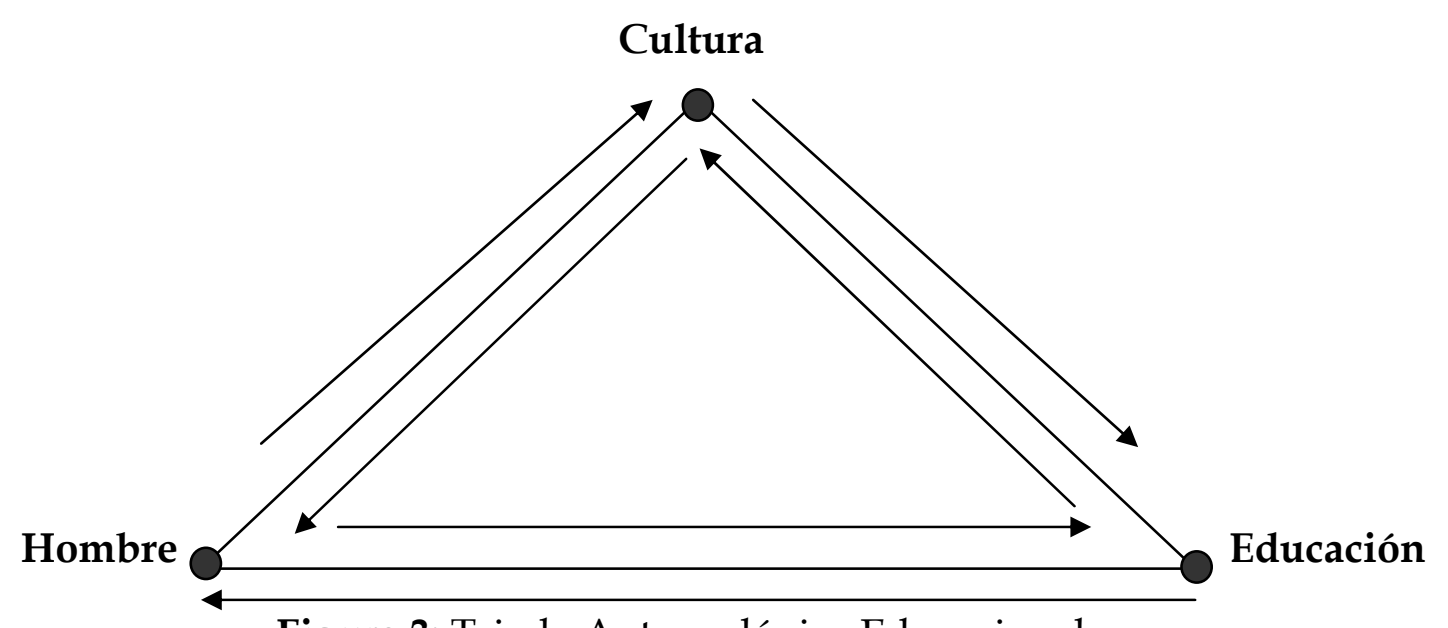

Figura 3: Triada Antropológica Educacional.

Fuente: Fullat (1995), adoptado por Guanipa (2010).

A partir del momento que surge el hombre en la naturaleza y programación genética de la vida biológica, también emerge la cultura hermenéutica, técnicas e instituciones, por lo cual se hizo necesaria la educación; el proceso educacional se convierte así en un elemento constitutivo de la esencia del hombre.

En relación a las disciplinas que apoyaron esta investigación, se consideró pertinente resaltar el principio de cooperación de Grice (1995), citado por Calsamiglia y Tusón (2001), la cual ofrece una explicación de la manera cómo se producen ciertos tipos de inferencias basadas en forma de enunciados convencionales o no, sobre lo que no está dicho pero, sin embargo, se quiere comunicar. Se centra, fundamentalmente, en el estudio de los procesos inferenciales situados, los profesores activan para entender los enunciados, a partir de formas que parecen transgredir los principios racionales y los alumnos respetan para poder cooperar y comprender con relativa facilidad y agilidad.

De la misma manera, esta investigación se apoyó en la teoría de la relevancia o pertinencia propuesta por Sperber y Wilson (1995), quienes presentan una explicación sobre el funcionamiento de los mecanismos cognitivos en la emisión de mensajes y sobre todo, la interpretación de los anunciados para que esta se realice con un máximo de eficacia y un mínimo costo de procesamiento a partir del reconocimiento de la información relevante de acuerdo con los factores contextuales donde un enunciado se produce. 
Igualmente, se considera relevante la teoría de los actos del habla propuesta por Austin en 1962, posteriormente desarrollada por Scarle (citados ambos por Calsamiglia y Tusón 2001). Se debe aclarar que los planteamientos de Austin, son uno de los principales fundamentos de la pragmática. Desde esta teoría se considera que hablar es hacer y cada enunciado emitido posee un significado literal o proposicional, una dimensión intencional y una dimensión que repercute en la audiencia.

Esta distinción entre lo que se dice, la intención con que se dice y el efecto de lo que se dice con esa intención, sitúa la interpretación de las intenciones en el marco de la conversación y, como consecuencia, se incorporan factores sociales y cognitivos al estudio de los enunciados, los cuales puedan adoptar formas más o menos directos o convencionales para expresar contenido. Desde sus orígenes, el pensamiento filosófico se ha preocupado por el lenguaje y la capacidad o mecanismo ocupado y desempeñado en la vida de los seres humanos, destacándose entre sus temas: el origen del lenguaje, su relación con el pensamiento, la manera como las palabras permiten o dificultan el acceso a las ideas y a su expresión.

\subsection{Proceso de comunicación en el salón de clases}

El proceso de comunicación en el aula, es un acto donde intervienen dos personas como actores principales (profesor y alumno) en un escenario académico mediados por una relación dialógica que facilita la comunicación. Es definido por Gómez (2002) como el conjunto de fases sucesivas de un fenómeno natural o de una operación artificial en tanto, Escandell (1993), considera que los procesos de comunicación conducen, desde la intención hasta la interpretación, a través de la expresión lingüística, teniendo en cuenta la información pragmática del emisor en este caso del profesor y del destinatario, el alumno y la relación social acción pedagógica existente entre esos dos sujetos de la enunciación. (Ver figura 4).

Además, la comunicación es una acción, donde se utiliza un texto entre dos o más personas, el sentido se crea entre quienes participan en esta actividad, pero no siempre se dicen las cosas de forma totalmente explícita, aun cuando se comparte como seres humanos y por lo tanto, se puede descansar en ese conocimiento compartido al emitir los enunciados. El texto según Martín (1998) es cohesivo porque es una unidad semántica donde se pueden establecer relaciones internas entre las partes, porque es un unidad pragmática en la cual que se pueden establecer relaciones con el contexto donde ocurre, para explotar así su potencial comunicativo. El texto en el discurso profesoral, ocupa el lugar central del evento pedagógico cuya unidad de análisis es la oración que lo caracteriza. 


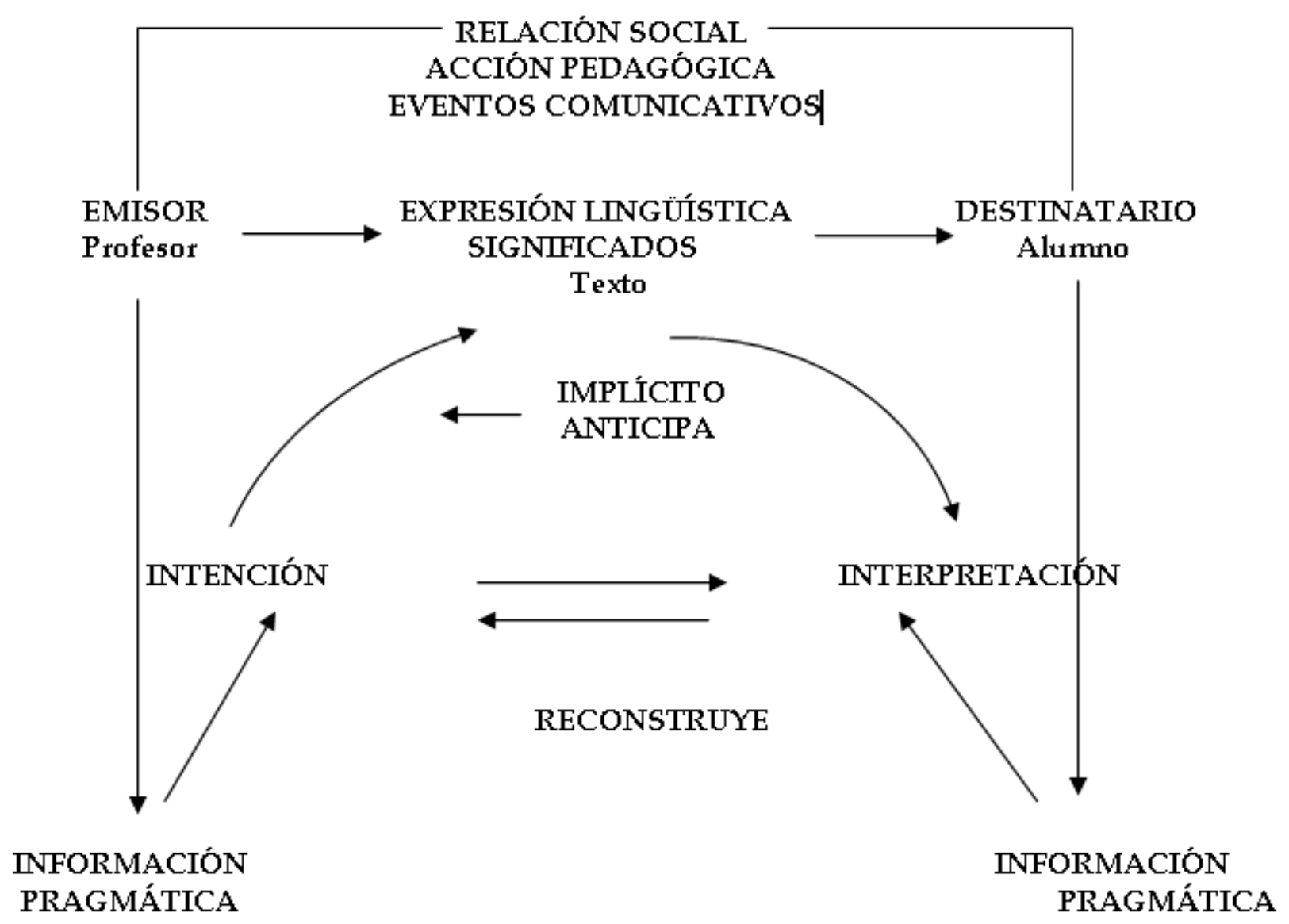

Figura 4: Proceso de Comunicación

Fuente: Escandell (1993) adaptado por Guanipa (2010)

Esto conlleva a realizar cálculos, sobre los cuales precisan Calsamiglia y Tusón (2001) "son las parcelas de la experiencia compartida con los interlocutores y a los que se pueden apelar de forma implícita en los mensajes" (p. 186). Esos cálculos pueden ser erróneos y llevar a la incomprensión o al malentendido, o bien, como es común, a la negociación de los parámetros contextuales donde se sitúan las manifestaciones de las intenciones para una hermenéutica adecuada.

Cabe considerar por otra parte, existen diferentes modelos que orientan el proceso de comunicación entre los cuales se destacan los siguientes: según Gómez (2002) el primero de ellos y posiblemente el más conocido, es el retórico de Aristóteles (384 322 a. Cristo) quien definió científicamente la comunicación por primera vez, como "la búsqueda de todos los medios posibles de persuasión" (p. 13) 


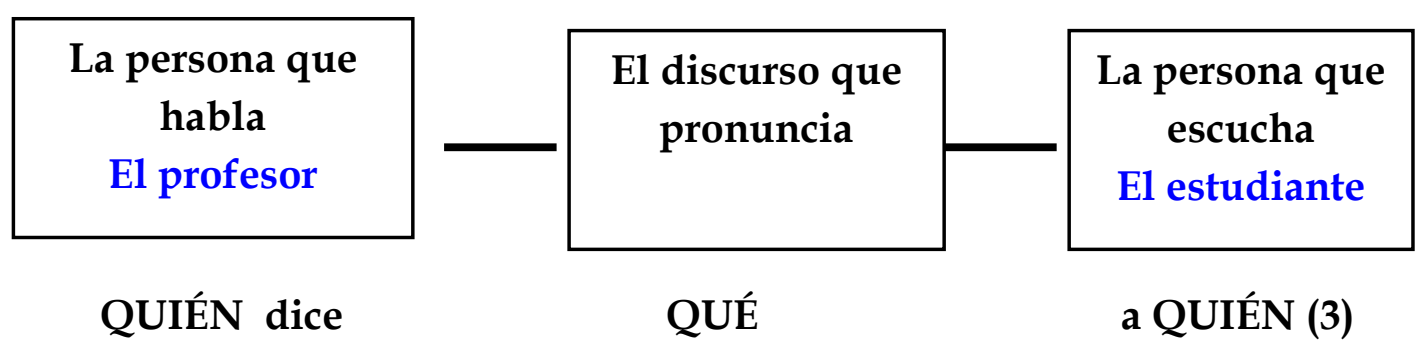

Figura 5: medios posibles de persuasión

Fuente: Gómez (2002) Adaptado por Guanipa (2010)

Posteriormente, en la década de 1930 en los Estados Unidos, un grupo de científicos sociales se interesó por los estudios de la comunicación, motivo por el cual se conoce a sus integrantes como los padres de la comunicación: Lazarsfeld, Lewin, Lasswell y Hovland.

Lasswell concretamente, incluye dos elementos más a los tres mencionados por Aristóteles: el canal por donde viajan los mensajes y los efectos que estos producen para representar mejor el proceso original de comunicación, es decir, (1) emisor, (2) mensaje, (3) canal, (4) receptor y los (5) efectos causados en este último:

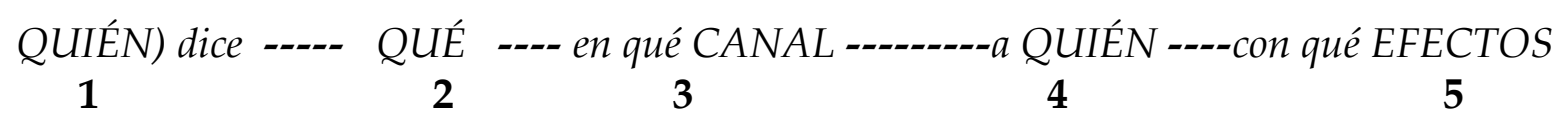

En la década siguiente, Nixon citado por Gómez (2002) modifica el modelo de Harold Lasswell, introduciendo dos elementos más en el proceso de comunicación: las intenciones que motivaban al comunicador y las condiciones en que se recibía el mensaje.

Con qué INTENCIONES (6) QUIÉN (1) dice QUÉ (2) en qué CANAL (3) a QUIÉN bajo qué CONDICIONES (7) con qué EFECTOS (5).

Además de los elementos presentados arriba, Calsamiglia y Tusón (2001) incluyen el de qué manera, relacionándolo con el proceso de interpretación, pero muchas veces en las inferencias como receptores se considera la manera sólo desde el punto de vista de la intención mas no de la capacidad; cabría preguntarse si el emisor posee o no recursos para expresar lo dicho de otra manera y a partir de allí elaborar la hipótesis, teniendo cierta responsabilidad social. Igualmente, el emisor debe entrenar su instrumento de comunicación (se habla sólo en este caso de la voz, el habla y el cuerpo). Esto con el fin de elegir la manera más conveniente de decir un propósito, materializándolo en códigos lingüísticos y/o extralingüísticos, la manera como se dice un texto es muchas veces producto de la competencia o incompetencia comunicativa.

Al discernir sobre este aspecto con profesionales de la comunicación, se ha visto cómo el canal interno se considera implícito en la figura del emisor, y aunque es evidente, no se discute que el emisor lo posee, se cree ser hora de explicitarlo y caracterizarlo, lo cual daría lugar a una mejor evaluación de las interacciones y los procesos 
comunicacionales. A continuación se presenta en la figura 5 propuesta por Chela Flores (2001) una de las más completas descripciones de la situación de comunicación. De otro modo, en cuanto a los interlocutores, abarca sólo su relación (a) social: de jerarquía y sabiduría; y (b) física: de distancia o cercanía.

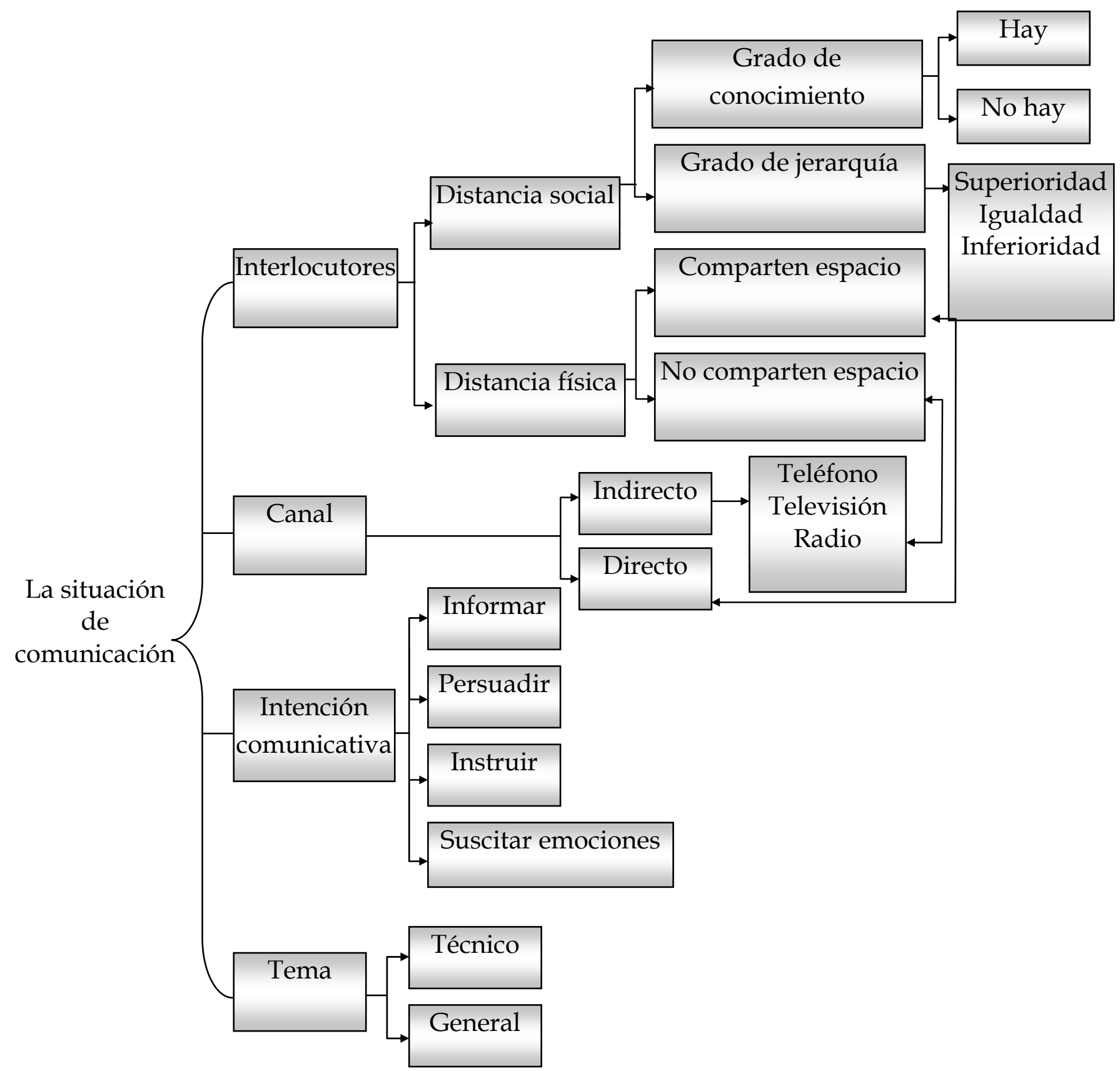

Figura 6: Descripción de la situación de comunicación.

Fuente: Chela Flores (2002)

No obstante, en la casilla correspondiente a la sabiduría se contempla el conocimiento de la norma lingüística, la forma o las habilidades articulatorias o gestuales; pero se duda que su referencia no sea sólo hacia los saberes socioculturales compartidos por 
ambos. Quizás lo implicado sea el conocimiento común del código empleado, esto se traduce simplemente a que si es escrito el receptor debe saber leer, por ejemplo.

Según Martínez (1994), en la literatura existente, canal se traduce como un medio material utilizado por el emisor en la transmisión de un mensaje. Los canales de comunicación son: la palabra, el escrito, la imagen, el sonido y el acto de presencia. Puede ser natural-fisiológico (por ejemplo, el lenguaje hablado, en la relación interpersonal, mediante las vibraciones del aire son percibidas por el tímpano de un destinatario próximo) y artificial-técnico (por ejemplo, cine, radio, televisión, teléfono, teletipo, telefoto, entre otros). Ahora bien, cabría preguntarse: ¿será que la diferencia entre un texto escrito y uno oral es que en el primero el código es gráfico y el canal un papel, y en el segundo el código es sonoro y el canal es el aire a través del cual se propagan las ondas sonoras?

Esta parece haber sido la relación hasta ahora expuesta, pero es obvio, el grafismo del código escrito o la sonoridad del oral cambian y se hacen más o menos exitosos de acuerdo con el dominio que el emisor tenga no sólo de los códigos mismos (esto se reduce a tener buena caligrafía o un timbre agradable) sino también al vehículo, el cual le permite que tanto éstos como todos los elementos implícitos (conocimiento de la norma lingüística y conveniencia de sus variaciones, control de la tensión o relajación muscular, habilidad articulatoria, entre otros) sean empleados.

Una vez reconocido el panorama que determinará la comunicación, el codificador se debe disponer a la emisión, pero aparente y lamentablemente no se ha entendido lo siguiente: antes de iniciar el proceso de comunicación se debe captar la atención del receptor y luego mantenerla para que el proceso ocurra, y es ésa precisamente la debilidad manifestada en los hablantes públicos. Es aquí precisamente donde entra el canal interno quien se describirá a continuación.

Para lograr favorablemente la inclusión del canal interno en la esquematización del proceso comunicacional, éste no debe presentarse no en forma lineal $u$ horizontal, pues se reconoce que dicho canal le pertenece al emisor y por lo tanto no está al mismo nivel de alguno de los elementos considerados hasta ahora. Tampoco se considera estén al mismo nivel de los efectos, pues son propios del receptor, ni la intención, también de ella es dueño el emisor.

Algo semejante plantea O'Sullivan (1996) organizando los elementos propuestos por Nixon haciendo depender unos de otros. En este punto se reorganizan los elementos del modelo de comunicación el cual incluye con firmeza el canal interno (Figura 6) dependiente del emisor para revalorarlo como codificador a través de su competencia. 


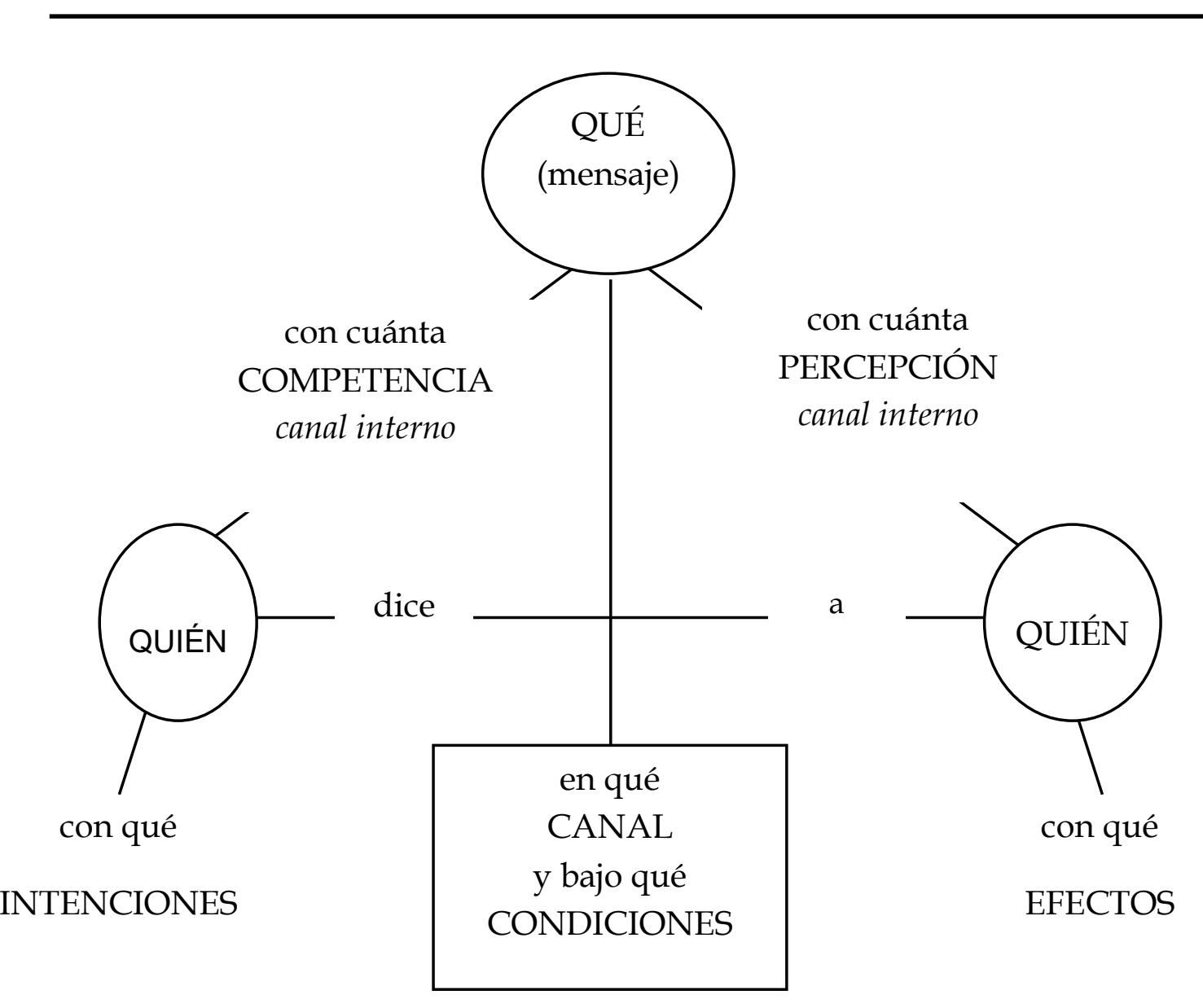

Figura 7: Modelo de comunicación que incluye el canal interno.

Fuente: Chela Flores (2002)

Según este gráfico, se ofrece al receptor un canal, actuando como filtro de información o capacidad de percepción a través del cual se inicia la interpretación, y permite visualizar simétricamente el diseño del proceso donde los dos elementos principales, emisor y receptor, puedan intercambiarse cuando ocurra la interacción, dando como resultado el mensaje. Aunque este modelo no contempla todos los rasgos previstos en la Figura 5, cubre los elementos primordiales de la comunicación y posibilita la evaluación de las herramientas con las cuales cuenta o debe contar un emisor para ser competente. Además, demuestra la forma del mensaje, la cual no depende únicamente de su concepción -como es expresado por muchos estudiantes, docentes y teóricos de la comunicación social- ello es sólo una porción de su cuerpo, esta, junto con el aporte del receptor más el del contexto, termina de formarse.

\subsection{Procedimientos metodológicos para interpretar el discurso profesoral}

Antes de entrar en el trabajo práctico de la investigación se consideró pertinente presentar ciertas conceptualizaciones las cuales ayudarán a un mejor entendimiento de su desarrollo. Sobre el discurso se han elaborado una serie de definiciones, entre ellas se destacan las siguientes: Bakstine (citado por Martínez, 1994) lo define como "el producto de la interacción de los individuos socialmente organizados" (p. 33) y añade, 
aun en el caso de no existir interlocutor real (discurso interior o pensamiento), éste es reemplazado por la clase social a la cual el locutor real pertenece.

Atendiendo a estas consideraciones, la estructura del discurso será determinada por las condiciones reales en las cuales éste se realiza, es decir, sobre todo por la situación social inmediata y el medio social más amplio; por el hecho de proceder de alguien y dirigirse a alguien. En este contexto, Martínez (1994) establece dos clases de análisis en los eventos comunicativos diferentes pero complementarios: (a) análisis textual; (b) análisis discursivo; y dos clases de procedimientos metodológicos también complementarios: (a) la cohesión y (b) la coherencia.

Beangrande y Dressler (1997) proponen un modelo con siete estándares, condiciones que debe reunir cualquier texto: cohesión, coherencia, intencionalidad, aceptabilidad, situacionalidad, intertextualidad e informatividad. Dos de estos estándares tienen relación de forma especial con la textura del discurso: la coherencia y la cohesión, utilizados como sinónimos para indicar la red de relaciones semántico-pragmáticas de un texto.

Aparte de esta investigación, se asume el criterio de Calsamiglia y Tusón (2001), quienes consideran ambos conceptos relacionados entre sí por inclusión de uno en otro en el sentido siguiente: "La coherencia es un concepto que se refiere al significado del texto en su totalidad, abandonando tanto las relaciones de la palabra con el contexto, como las relaciones entre palabras en el interior del mismo texto" (p. 222).

Según las autoras citadas, la coherencia alude a la estabilidad y la consistencia temática subyacente, asociada a la macroestructura (contenido), a la superestructura (esquema de organización) del texto, a su anclaje enunciativo (protagonistas, tiempo y espacio) y a las inferencias que activan los hablantes para interpretarlo a partir de conocimientos previos.

De otro modo, la cohesión es un concepto referido a uno de los fenómenos propios de la coherencia, de las relaciones particulares y locales entre elementos lingüísticos, tanto los remitentes entre sí, como los que tienen la función de conectar y organizar. Así, la coherencia incluye la cohesión y se puede considerar una propiedad fundamental dando cobertura al conjunto de significaciones del texto, y a un principio necesario donde un texto sea definido como tal.

Visto de esta forma, como se dijo anteriormente, la cohesión según Martín (1998) alude procesos internos porque son unidades semánticas en las cuales se establecen relaciones entre las partes. En cambio lo coherente, se refiere a la relación del texto con el contexto situacional si establecen las relaciones con el contexto. Por consiguiente, el texto es una unidad semántica y pragmática por ello tiene dos tipos de significados.

Estas ideas, invitan a reflexionar sobre el discurso profesoral donde el significado del texto ocupa el lugar central en el contexto cognitivo de los estudiantes durante el desarrollo de los eventos comunicativos en el salón de clases. Por ello, la hermenéutica 
da cuenta de la organización del texto en el discurso permitiendo su interpretación, comprensión y explicación habida cuenta, de su significado semántico y pragmático.

Se plantea entonces, el significado gramatical, es decir, la cohesión del texto dependerá de acuerdo con Martín (1998) de las reglas postuladas dentro de la gramática; donde el significado pragmático, referido a la coherencia del texto responde a las reglas fijadas dentro de una comunidad. Estas dos reglas (gramatical y contextual - social) interactúan para que el texto discursivo del profesor en el contexto cognitivo de los estudiantes, pueda asignársele un sentido determinado con significado que contemple simultáneamente ambas dimensiones.

De hecho, dentro del significado contextual (coherencia) están contempladas todas las variables extralingüísticas determinantes (cohesión) para entender, interpretar y comprender (hermenéutica) el discurso profesoral interactuando con el conocimiento de los estudiantes de la Escuela de Comunicación Social. Para plantear el análisis del contenido del texto, Van Dijk (1998) proporciona una aproximación analítica a partir del conjunto del texto, entendiéndose éste como una unidad global. En vez de partir de la oración y sus componentes, parte de la hipótesis de unidades superiores de contenido a las cuales llama macroestructura, esta es la proposición subyacente que representa el tema o tópico de un texto y constituye la síntesis de su contenido.

Un modo de identificar la coherencia en su macroestructura (contenido del texto), radica en considerarla como una reconstrucción realizada por la persona que interpreta (los estudiantes). Para explicarla, Van Dijk (1998) recurre al modelo usual de la lógica proposicional, utilizado en la semántica, este articula el contenido en predicado y argumentos. Dicha propuesta se genera a partir de la asunción de la estructura global proveniente de la capacidad de resumir y de recordar un texto, de reducir su significado a lo esencial.

Junto al contenido referencial, para lograr un resumen donde se incluya la significación semántica y pragmática total del discurso profesoral se ha de incorporar el propósito del evento comunicativo, los alumnos y la intención para ser producidos. Según Fayol citado por Clasamiglia y Tusón (2001), el resumen es un caso de paráfrasis selectiva, que se hace a partir de un objetivo. De esta manera, al manejar y reformular el contenido del evento comunicativo de base, se produce una elección y esta, para el posible destinatario es esencial y adecuado, así como también se adecuará al propósito del autor de informar, enseñar, orientar o criticar.

Los textos de reformulación son habituales en las prácticas comunicativas, se encuentran generalmente en los procesos de enseñanza y en la divulgación del saber. También aparece de manera pragmática en las noticias periodísticas, en las cuales se presenta la información en tres tiempos: el titular, la entrada y el cuerpo del artículo. Los tres proporcionan lo que Van Dijk (1998) denomina tema o tópico del texto, resumen, desarrollo o expansión. En las últimas décadas, al hablar del discurso se hace referencia a una forma de acción entre las personas, la cual se articula a través del uso lingüístico contextualizado, ya sea oral, escrito o actuado. Sin duda, el discurso es 
parte de la vida social, hablar o escribir no es otra cosa que construir piezas textuales orientadas a unos fines, los cuales se dan en interdependencia con el contexto lingüístico, local, cognitivo y sociocultural.

El discurso lo describe Fairclough y Wodak (1997) como: "Práctica social con una relación dialéctica entre un evento discursivo particular y la situación; entre la institución y la estructura social que lo configuran. El discurso es socialmente constitutivo de situaciones, objetos de conocimiento, relaciones entre personas y entre grupos". (p. 258)

Aparte de los aspectos señalados, es importante destacar: las personas tienen a su disposición un repertorio comunicativo formado por una o más lenguas, por diferentes variedades lingüísticas y por otros instrumentos de comunicación. La lengua, como materia prima del discurso, ofrece a quienes la usan una serie de opciones fónicas, gráficas, morfosintácticas y léxicas, las cuales se deben elegir en el momento de interactuar discursivamente.

De acuerdo con Calsamiglia y Tusón (2001), dicha elección, está sujeta o no a un control consciente en concordancia con unos parámetros contextuales que incluyen la situación, los propósitos de los actores, es decir, de quién los emite y quién los recibe. Esto actores sociales, dice Van Dijk (1998) a través del discurso pueden formular conclusiones generales basadas en varias experiencias y observaciones; pueden describir acontecimientos pasados y futuros.

En consecuencia, en muchas situaciones de texto (oral, escrito o actuado) intra e intergrupal en el contexto educativo, los profesores y alumnos pueden contar o recordar sus ideas, sus creencias y compartirlas con el grupo. En las reflexiones anteriores, se evidencia un concepto de discurso tan general o difuso como el lenguaje, comunicación o sociedad, no obstante, el significado principal tal como se utilizó en esta investigación para referirse al texto o a la conversación concreta socialmente desplegada, fue una unidad de uso o actuación del lenguaje en la vida académica de la Escuela de Comunicación Social. Universidad Dr. Rafael Belloso Chacín, como contexto principal de este estudio.

Así pues, abordar un tema como el discurso profesoral, significa adentrarse en el entramado de las relaciones interpersonales, de las identidades, de los conflictos y de como se expresan los diferentes profesores y alumnos en el momento histórico social que vive Venezuela, con sus características socioculturales determinadas. Lo más significativo en este aspecto del estudio es la interpretación (hermenéutica) del discurso profesoral, el cual permitió entender las prácticas discursivas que se produjeron en el contexto cognitivo de los estudiantes, Escuela Comunicación Social, donde el uso de la palabra (oral, escrita o actuada) forma parte de las actividades didácticas desarrolladas durante los encuentros pedagógicos.

En el complejo mundo discursivo, el lenguaje humano se materializa a través de la oralidad y la escritura; en esta investigación, se abordaron las características específicas y destacadas del texto discursivo. Con ello se destacaron los rasgos más 
sobresalientes en las interrelaciones humanas entre alumnos y profesores de la Escuela Comunicación Social, Universidad Dr. Rafael Belloso Chacín.

\subsection{Elementos no verbales del discurso}

La modalidad oral o actos del habla son consustanciales al ser humano y constitutiva de la persona como miembro de una especie. Se produce en y con el cuerpo, aprovechando órganos del sistema respiratorio y de diferentes partes de la cabeza: labios, lengua, fosas nasales. También los movimientos de los ojos, diferentes expresiones faciales y otros movimientos corporales forman parte importante de la oralidad, así como las vocalizaciones y otros ruidos tal como se verán más adelante.

Son múltiples las funciones que tiene el habla desde los inicios de la vida social, esta modalidad ha ocupado un lugar importante en la vida pública, institucional o en la enseñanza formal. Actualmente, según Ong citado por Calsamiglia y Tusón (2001), la oralidad ocupa un lugar secundario, propiciado por los medios de comunicación de masas, por cuanto, la palabra es transmitida por altavoces o por pantallas y aún más, la posibilidad de grabar la voz permite conservar y reproducir lo dicho por personas importantes para la vida pública y privada. De otro modo, refiere Poyatos (1994):

Se ha creído poder analizar la realidad de los encuentros interactivos vivos, incurriendo en el análisis del discurso y de la comunicación interpersonal, sin ver la triple realidad del lenguaje vivo, hablado, que existe sólo como un continuo verbal paralingüístico - Kinésico, formado por sonidos y silencios; movimientos y posiciones estáticas, es decir, triple estructura básica de la comunicación. (p.130)

Esta situación de enunciación oral, se caracteriza por los siguientes rasgos:

a) La participación simultánea de las personas que intervienen en ella: interlocutores.

b) La presencia simultánea de quienes interactúan, se comparte el espacio y el tiempo de los interlocutores que participan cara a cara.

c) Los interlocutores activan, construyen y negocian en la interacción una relación interpersonal en sus características psicosociales.

Tradicionalmente se han descuidado los elementos consustanciales del discurso oral como son: el sonido de la voz, ruido, gestos, posturas, distancia entre personas involucradas en un evento comunicativo, entre otras. Al respecto expone Van Dijk (1997):

La articulación, la recepción auditiva o los fonemas pueden ser marginales para un típico analista del discurso que prefiere mirar las estructuras más allá de las palabras, frases u oraciones. Sin embargo el tono de la voz, el volumen y la entonación, son una rica fuente de variaciones por las cuales, se pueden controlar el énfasis, la prominencia o la característica distintiva de la opinión, la emoción y la posición social. (p. 255) 
Por consiguiente, si se ha de entender el discurso oral de los profesores de la Escuela Comunicación Social, Universidad Dr. Rafael Belloso Chacín en toda su complejidad, es menester, dar cuenta de lo que dicen, cómo lo dicen y cómo se mueven durante el proceso didáctico. En tal sentido Knapp (1998), recoge los aportes realizados por diversos autores sobre el tema y los agrupa bajo siete esquemas titulados como sigue: movimiento del cuerpo o comportamiento cinésico, características físicas, conductas táctiles, paralenguaje, proxémica, artefactos y factores del entorno. A continuación se desarrollarán algunos de los elementos más relacionados con la variable objeto del presente estudio.

\subsection{Elementos cinésicos en el discurso oral}

Cuando se habla de cinésica, se hace referencia a los movimientos y posiciones significativas durante el proceso de comunicación. Poyatos (1994), la define como los movimientos corporales y posiciones resultantes o alternativas de base psicomuscular, conscientes o inconscientes, somatogénicos o aprendidos de percepción visual, auditiva, táctil; los cuales aislados o combinados con las estructuras verbales o paralingüísticas poseen un valor comunicativo intencionado o no.

Refiere el mencionado autor, se pueden distinguir gestos, maneras y posturas incluidos en la cinésica desde los movimientos que acompañan los saludos, chasquidos, aplausos o pataleos, desde las palmaditas en la espalda hasta rascarse la cabeza, un levantamiento de cejas y los golpes en la mesa o la manera de golpear la puerta. De allí, pues, los gestos pueden sustituir a la palabra, concretar o repetir su significado, matizarla, contradecirla, sencillamente para acompañarla y hacer sentir a gusto a su interlocutor

Para efectos de esta investigación, el interés se centró en los gestos y posturas en la expresión de actitudes lingüísticas de los profesores ante la realidad comunicativa en el salón de clases, ello sirvió para mostrar la posición adoptada por los docentes frente a lo qué dicen y hacen con los alumnos de la Escuela Comunicación Social, Universidad Dr. Rafael Belloso Chacín.

La postura de las personas (en este caso de los profesores) se conforma a la disposición que adopte su interlocutor (los alumnos); existe pues, todo un código posicional entre las personas, se extiende hasta la manera como se sienta o duerme. El estudio de la comunicación no verbal, a través de posiciones, originó una ciencia denominada proxémica, la cual analiza minuciosamente las más pequeñas variaciones, estas se perciben en los cambios posicionales de las personas. En la tabla siguiente, se aprecia la manera como algunos estudios citados por Calsamiglia y Tusón (2001) clasifican los efectos comunicativos: 
Tabla 1: Conductas evaluadas como cálidas o frías

\begin{tabular}{|c|c|}
\hline Conductas cálidas del profesor & Conductas frías del profesor \\
\hline $\begin{array}{l}\text { - } \quad \text { Mira los ojos del alumno al hablar } \\
\text { - } \quad \text { Toca al alumno mientras habla } \\
\text { - } \quad \text { Se mueve hacia los alumnos al hablar } \\
\text { - } \quad \text { Mira a los alumnos de la cabeza a los pies } \\
\text { - } \text { Hace muecas } \\
\text { - } \quad \text { Mueve la cabeza afirmativamente } \\
\text { - } \quad \text { Lame los labios } \\
\text { - Hace gestos expresivos con las manos } \\
\text { mientras habla }\end{array}$ & $\begin{array}{ll}\text { - } & \text { Tiene la mirada perdida } \\
\text { - } & \text { Se burla de sus alumnos } \\
\text { - } & \text { Se aleja de los alumnos al hablar } \\
\text { - } & \text { Finge bostezar } \\
\text { - } & \text { Frunce el entrecejo } \\
\text { - } & \text { Mira a techo } \\
\text { - } & \text { Se limpia las uñas } \\
\text { - } & \text { Hace sonar los dedos } \\
\text { - } & \text { Juega con el cabello }\end{array}$ \\
\hline
\end{tabular}

Fuente: Clore y otros citados por Calsamiglia y Tusón (2001) (Adaptado por Guanipa -2010-)

\subsection{Elementos proxémicos en el discurso oral.}

Sobre la base de las ideas expuestas, Calsamiglia y Tusón (2001), al referirse a la proxémica consideran: "es básicamente la manera en que el espacio se concibe individual y socialmente, a cómo los participantes se apropian del lugar donde se desarrolla un intercambio comunicativo y a cómo se distribuyen" (p. 49). Relacionado, por lo tanto, con el lugar ocupado por profesores y alumnos de la Escuela Comunicación Social, respectivamente, en los posibles cambios de lugar de alguno de los participantes, en el valor que se atribuye a estar situados en el salón de clase y a la posibilidad de moverse o no. Igualmente, con la distancia que mantenida entre si, tanto profesores como alumnos en el intercambio comunicativo en el proceso didáctico en el aula.

Esta distancia puede variar por diferentes motivos, pues depende del tipo de evento suscitado. En un aula, normalmente existe un espacio asignado a los alumnos y a los profesores no obstante, quien enseña puede decidir sentarse frente o delante de su escritorio, encima o debajo de una tarima o bien, pasear entre las sillas de los alumnos combinando sus actuaciones en su contexto situacional. Dentro de esta perspectiva, se debe destacar: las personas asocian significados psicosociales y culturales a esos lugares y espacios, pues los separa o acerca a los demás de forma física y simbólica, los cuales pueden ser interpretados como muestra de frialdad o como distancia normal.

En ese sentido Knapp (1980) distingue cuatro posibles categorías donde se entiende el espacio normal: (a) íntimo, (b) casual-personal, (c) social -consultivo y (d) público. Ahora bien, lo que en un grupo cultural se considera un comportamiento proxémico adecuado para cada una de esas cuatro categorías puede variar según se considere adecuado en otros grupos 


\subsection{Elementos paraverbales del discurso}

Entre la palabra y el gesto existe una frontera signada con una serie de elementos vocales no lingüísticos, ellos se producen con los mismos órganos del aparato de fonación humano, sin embargo, no se consideran parte de la lengua. Esos elementos son la voz y las vocalizaciones.

\subsection{Calidad, intensidad y timbre de la voz}

Pueden indicar el sexo, la edad, los estados físicos como la afonía, el resfriado nasal, el asma, el ánimo y la relajación. De acuerdo con Tusón y Unamuno, (1999), la calidad de la voz, se puede modular para conseguir efectos o manifestar intenciones deseadas. Así, un mensaje puede ser susurrado, dicho con ironía, seriedad o broma (ver tabla $n^{\circ}$ 2)

Tabla 1: Características de las expresiones vocales

\begin{tabular}{llllllll}
\hline $\begin{array}{l}\text { Estado } \\
\text { Afectivo }\end{array}$ & Volumen & Tono & Timbre & Velocidad & Inflexión & Ritmo & Elocución \\
\hline Afecto & Suave & Grave & Resonante & Lenta & Firme & Regular & Ligada \\
Cólera & Alto & Agudo & Brillante & Rápida & Irregular & Irregular & Entrecortada \\
Alegría & Alto & Agudo & Moderado & Rápido & Hacia arriba & Irregular & ----------- \\
Tristeza & Suave & Grave & Resonante & Lenta & Hacia abajo & Irregular & Ligada \\
\hline
\end{tabular}

Fuente: Davitz adoptado por Knapp (1980) Adoptado por Guanipa (2010)

\subsection{Las vocalizaciones}

Se refieren a los sonidos o ruidos emitidos por la boca denominados palabras, desempeñando funciones comunicativas, las cuales pueden servir para asentir, mostrar desacuerdo o impaciencia, para pedir la palabra, mostrar admiración o desprecio hacia quien habla o hacia lo dicho o pronunciado. Normalmente, se combinan gestos faciales o de otras partes del cuerpo (manos, hombros, ojos, piernas, rostros, labios) con un valor interactivo, los cuales al interpretarlos de manera equivocada puede ser fuente de malentendidos o incomprensiones más globales.

Algunas de estas vocalizaciones son: las exhalaciones (suspiros, bufidos), carraspeo, silbidos, tos, eructos, risas, llantos y las onomatopeyas (paf, pum, buf). El significado de tales elementos, varía en cada situación y grupo cultural, pues si se descuidan pueden producir una visión parcial o limitada de lo que son los usos comunicativos, igualmente, conducir a cometer errores de producción y de interpretación a quienes se les comunica un determinado mensaje. A continuación se enumeran algunas vocalizaciones: 
Tabla 2: Las vocalizaciones

- Inhalaciones - Tos

- Exhalaciones - Eructos

- Carraspeo - Ruidos de relleno

- Silbidos - Risas de burla o alegría

- Chasquidos - Llantos de pena o alegría

Fuente: Calsamiglia y Tusón (2003) adoptado por Guanipa (2010)

\section{RESULTADOS DE LA INVESTIGACIÓN}

En esta fase de la investigación, se presenta el análisis estadístico de la variable elementos del proceso comunicativo del discurso del profesor universitario, que sustentan, la numerología y la experiencia de la investigadora, a fin de enriquecer la interpretación y comprensión de la información obtenida a través de las técnicas aplicadas a la muestra objeto de estudio.

Al confrontar los datos resultantes obtenidos en la aplicación de los cuestionarios y entrevistas a estudiantes, profesores y coordinadores de cátedra, se observa una relación significativa respecto al porcentaje alcanzado en función a las alternativas de respuesta correspondientes. El estudio realizado consideró la población estudiantil representada por 2592, cuyos resultados más significativos reflejan lo siguiente:

Variable: Elementos del proceso comunicativo cuyas dimensiones a analizar son: canales de comunicación, eventos comunicativos en los encuentros pedagógicos, procedimientos para interpretar el discurso, elementos no verbales y paraverbales de los actos del habla

\subsection{Dimensión canales de comunicación}

En la tabla y el gráfico que se presentan, se observa que el 100\% de los profesores dicen utilizar diferentes canales de comunicación para que los estudiantes comprendan su discurso, el $60 \%$ de los coordinadores estuvo de acuerdo, sin embargo sólo el $47 \%$ de los estudiantes coincide con esta respuesta mientras que, el $33 \%$ ni de acuerdo ni en desacuerdo y el $20 \%$ en desacuerdo que al relacionarlo con la muestra total (2592) se traduce en que 520 estudiantes sienten que los profesores no utilizan diferentes canales de comunicación en discurso en el aula. 
Tabla 2: Canales de comunicación

\begin{tabular}{|c|c|c|c|c|c|c|c|c|c|c|}
\hline \multicolumn{2}{|c|}{ Categorías } & \multicolumn{3}{|c|}{ ACUERDO } & \multicolumn{3}{|c|}{ NEUTRAL } & \multicolumn{3}{|c|}{ DESACUERDO } \\
\hline Indicadores & items & $\underset{\%}{\text { COORD }}$ & $\begin{array}{c}\text { PROF } \\
\%\end{array}$ & $\underset{\%}{\text { ESTUD }}$ & $\underset{\%}{\text { COORD }}$ & $\begin{array}{c}\text { PROF } \\
\%\end{array}$ & $\underset{\%}{\text { ESTUD }}$ & $\underset{\%}{\text { COORD }}$ & $\underset{\%}{\text { PROF }}$ & $\underset{\%}{\text { ESTUD }}$ \\
\hline 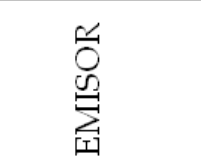 & 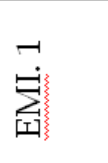 & 60 & 100 & 47 & 40 & 00 & 33 & 00 & 00 & 20 \\
\hline
\end{tabular}

Fuente: Elaboración propia (2010)

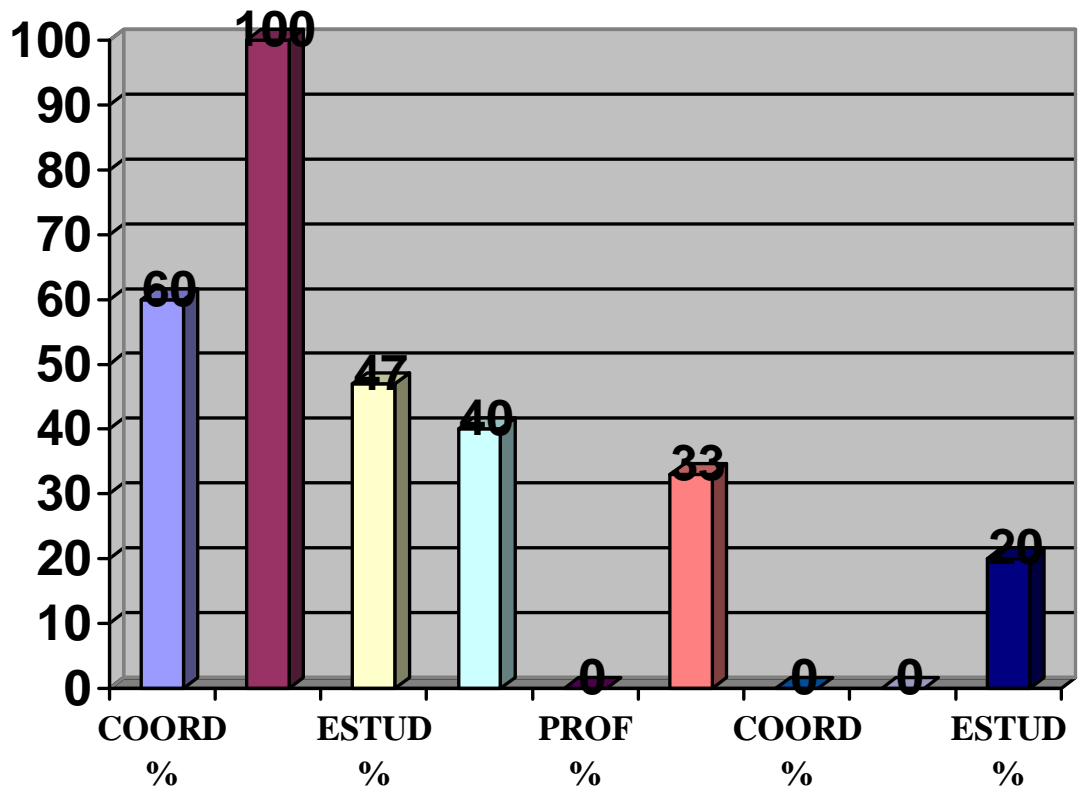

\begin{tabular}{|l|}
\hline$\square$ COORD \% \\
$\square$ PROF \% \\
$\square$ ESTUD \% \\
$\square$ COORD \% \\
$\square$ PROF \% \\
$\square$ ESTUD \% \\
$\square$ COORD \% \\
$\square$ PROF \% \\
$\square$ ESTUD \% \\
\hline
\end{tabular}

Figura 1. Comportamiento de las incidencias de los programas televisivos Fuente: Elaboración propia (2010)

En este respecto, Escandell ya para el año 1993 señalaba que los elementos del proceso comunicativo, conducen desde la intención hasta la interpretación de los textos, a través de la expresión lingüística, teniendo en cuenta la información pragmática del emisor en este caso el profesor, del destinatario es decir el alumno y, la relación social que se traduce en la acción comunicativa pedagógica. Cabría preguntar entonces, si el profesor como ente emisor, posee o no, recursos para expresar lo dicho en clase de manera diferente.

\subsection{Dimensión eventos comunicativos en los encuentros pedagógicos}

En cuanto a los eventos comunicativos en los encuentros pedagógicos, la mayoría de los profesores en un 91\% y los coordinadores en un 60\% están de acuerdo en afirmar que la manera como se desarrollan los eventos comunicativos en los encuentros pedagógicos agrada a los estudiantes, no obstante las respuestas de los estudiantes muestran una situación muy diferente puesto que datos son totalmente contradictorios 
pues, dicen estar de acuerdo solo un 41\% mientras que el 31\% no están de acuerdo ni en desacuerdo $\mathrm{y}$, aunque el $18 \%$ se podría considerar como no representativa al relacionarlo con la muestra estudiada se traduce en 466 alumnos que se muestran en desacuerdo.

Tabla 3: Eventos comunicativos en los encuentros pedagógicos

\begin{tabular}{|c|c|c|c|c|c|c|c|c|c|c|}
\hline \multicolumn{2}{|c|}{ Categorías } & \multicolumn{3}{|c|}{ ACUERDO } & \multicolumn{3}{|c|}{ NEUTRAL } & \multicolumn{3}{|c|}{ DESACUERDO } \\
\hline Indicadores & items & $\begin{array}{c}\text { COORD } \\
\%\end{array}$ & $\begin{array}{c}\text { PROF } \\
\%\end{array}$ & $\begin{array}{c}\text { ESTUD } \\
\%\end{array}$ & $\begin{array}{c}\text { COORD } \\
\%\end{array}$ & $\begin{array}{c}\text { PROF } \\
\%\end{array}$ & $\begin{array}{c}\text { ESTUD } \\
\%\end{array}$ & $\begin{array}{c}\text { COORD } \\
\%\end{array}$ & $\begin{array}{c}\text { PROF } \\
\%\end{array}$ & $\begin{array}{c}\text { ESTUD } \\
\%\end{array}$ \\
\hline 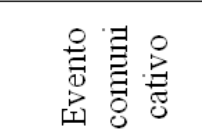 & 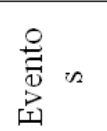 & 60 & 91 & 41 & 40 & 08 & 31 & 00 & 00 & 18 \\
\hline
\end{tabular}

Fuente: Elaboración propia (2010)

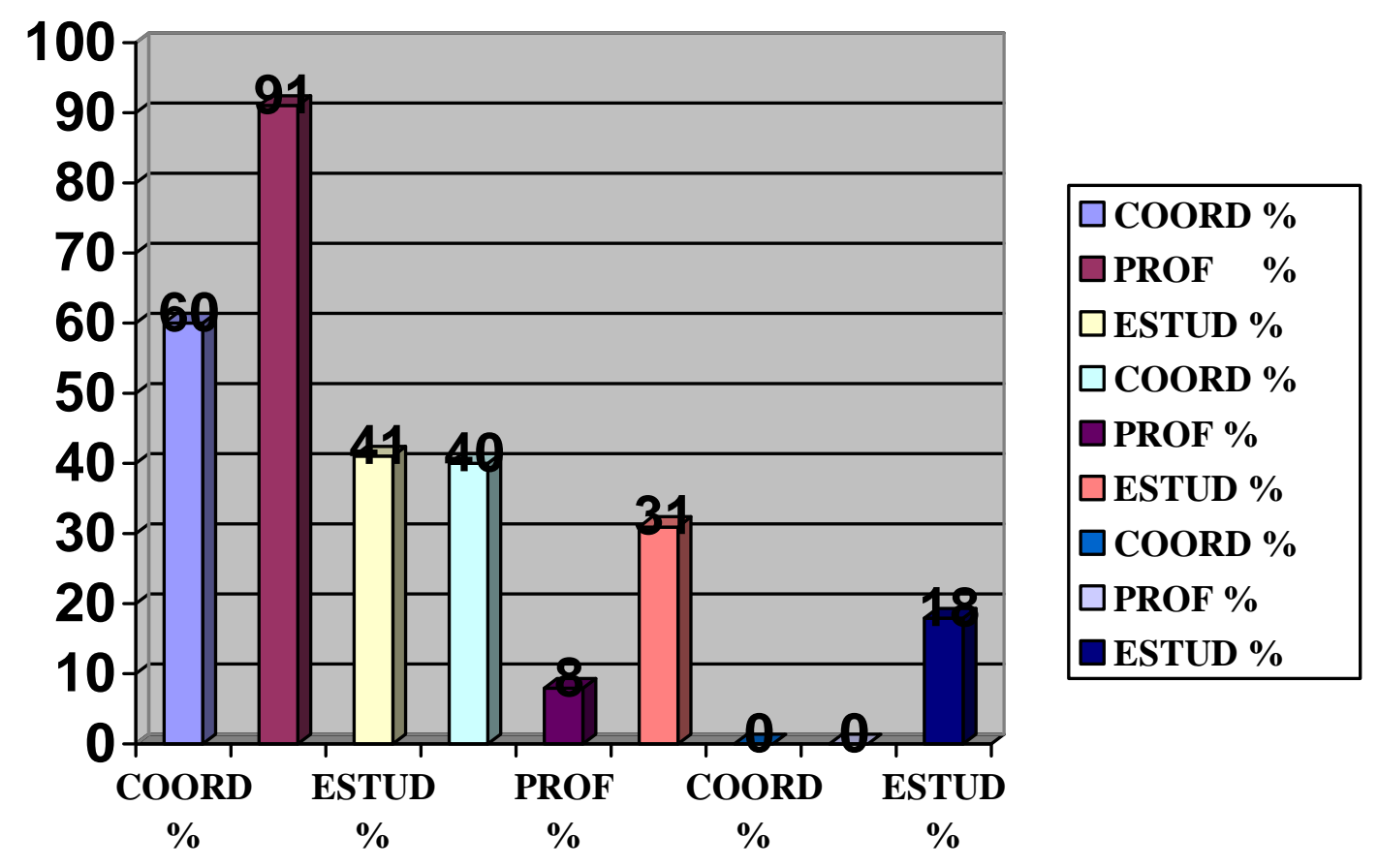

Figura 2. Comportamiento de las incidencias de los eventos comunicativos Fuente: Elaboración propia (2010)

En ese sentido, Fullat (1995) considera a la educación como "un cuestionamiento de lo que se hace y se dice en los campos educativos y pedagógicos en general" (p. 91). La filosofía de la educación tiene como uno de los cuidados fundamentales completar las insuficiencias de las ciencias y tecnologías particulares de la educación. Esta disciplina toma dos orientaciones: (a) saber lo que se dice y (b) saber lo que se hace en el contexto cognitivo. Los eventos comunicativos durante los encuentros pedagógicos según el principio de cooperación propuesto por Grice (1995) ofrece la explicación de la manera cómo se producen ciertos tipos de inferencias basadas en forma de enunciados convencionales o no, sobre lo que no está dicho pero, sin embargo, se quiere comunicar. 


\subsection{Dimensión procedimientos para interpretar el discurso}

Esta dimensión se trabajó solo con profesores y estudiantes. En la tabla que se presenta se aprecia que los profesores en un $82 \%$ dicen están de acuerdo que el conocimiento previo de los alumnos es coherente con su discurso mientras, los estudiantes lo están en un $41 \%$. E $36 \%$ respondió de una manera indiferente y el $23 \%$ es decir, 586 estudiantes están en desacuerdo.

Dimensión: Procedimientos para interpretar el discurso

Tabla 4: Coherencia del conocimiento del estudiante con los del profesor (I)

\begin{tabular}{|c|c|c|c|c|c|c|c|}
\hline \multicolumn{2}{|c|}{ Categorías } & \multicolumn{2}{|c|}{ ACUERDO } & \multicolumn{2}{|c|}{ NEUTRAL } & \multicolumn{2}{|c|}{ DESACUERDO } \\
\hline Indicadores & items & PROF & $\begin{array}{c}\text { ESTUD } \\
\%\end{array}$ & PROF \% & $\begin{array}{c}\text { ESTUD } \\
\%\end{array}$ & $\underset{\%}{\text { PROF }}$ & $\begin{array}{c}\text { ESTUD } \\
\%\end{array}$ \\
\hline COHERENCIA & COHER & 82 & 41 & 4 & 36 & 14 & 23 \\
\hline
\end{tabular}

Fuente: Elaboración propia (2010)

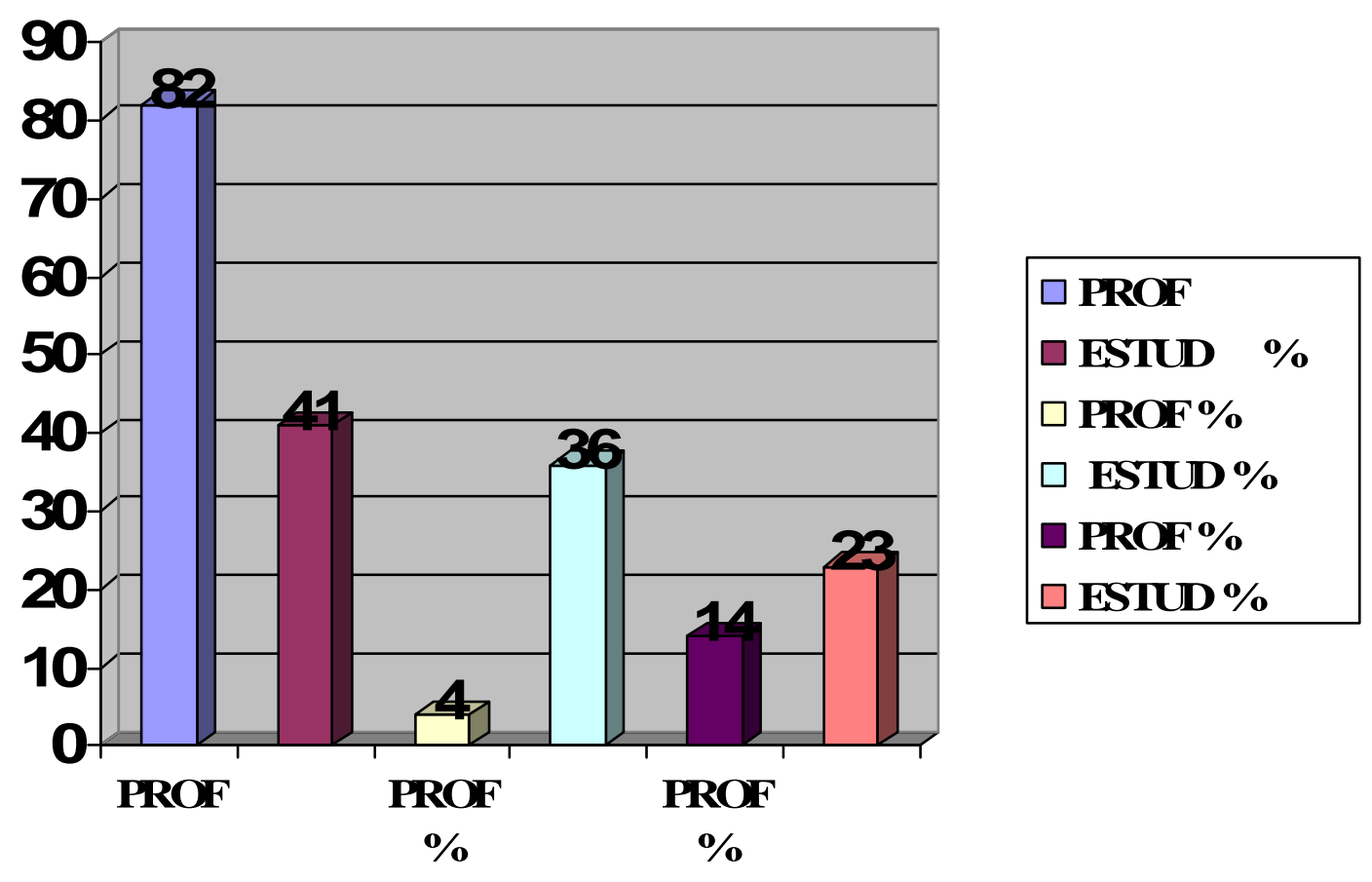

Figura 3. Comportamiento del conocimiento de los estudiantes Fuente: Elaboración propia (2010)

Al respecto, plantean Calsamiglia y Tuson (2001) que la coherencia es un concepto que se refiere al significado del texto en su totalidad, abandonando tanto las relaciones de la palabra con el contexto, como las relaciones entre palabras en el interior del mismo texto. Asimismo, Beaugrande y Dresler (1997) proponen un modelo para los eventos comunicativos con siete estándares, condiciones que debe reunir cualquier texto: cohesión, coherencia, intencionalidad, aceptabilidad, situacionalidad, intertextualidad 
e informatividad; dos de estos estándares tienen relación de forma especial con la textura del discurso y que incluso son indicadores de esta dimensión: la coherencia y la cohesión, utilizados como sinónimos para indicar la red de relaciones semánticopragmáticas de un texto.

Por otro lado, un $82 \%$ de los encuestados (profesores) respondieron que el contenido del discurso profesoral es entendido por los alumnos como una unidad global, no obstante, los estudiantes no lo creen así, un 57\% está de acuerdo, un $24 \%$ neutral y $19 \%$ en desacuerdo.

Dimensión: discurso profesoral es entendido por los alumnos como una unidad global

Tabla 5: Coherencia del conocimiento del estudiante con los del profesor (II) 田

\begin{tabular}{cccccccc}
\multicolumn{1}{c}{ Categorías } & & \multicolumn{2}{c}{ ACUERDO } & \multicolumn{3}{c}{ DESACUERDO } \\
Indicadores & items & PROF & $\begin{array}{c}\text { ESTUD } \\
\text { NEUTRAL }\end{array}$ & $\begin{array}{c}\text { PROF } \\
\text { \% }\end{array}$ & $\begin{array}{c}\text { ESTUD } \\
\%\end{array}$ & $\begin{array}{c}\text { PROF } \\
\%\end{array}$ & $\begin{array}{c}\text { ESTUD } \\
\%\end{array}$ \\
\hline COHERENCIA & COHER & 82 & 57 & 4 & 24 & 14 & 19
\end{tabular}

Fuente: Elaboración propia (2010)

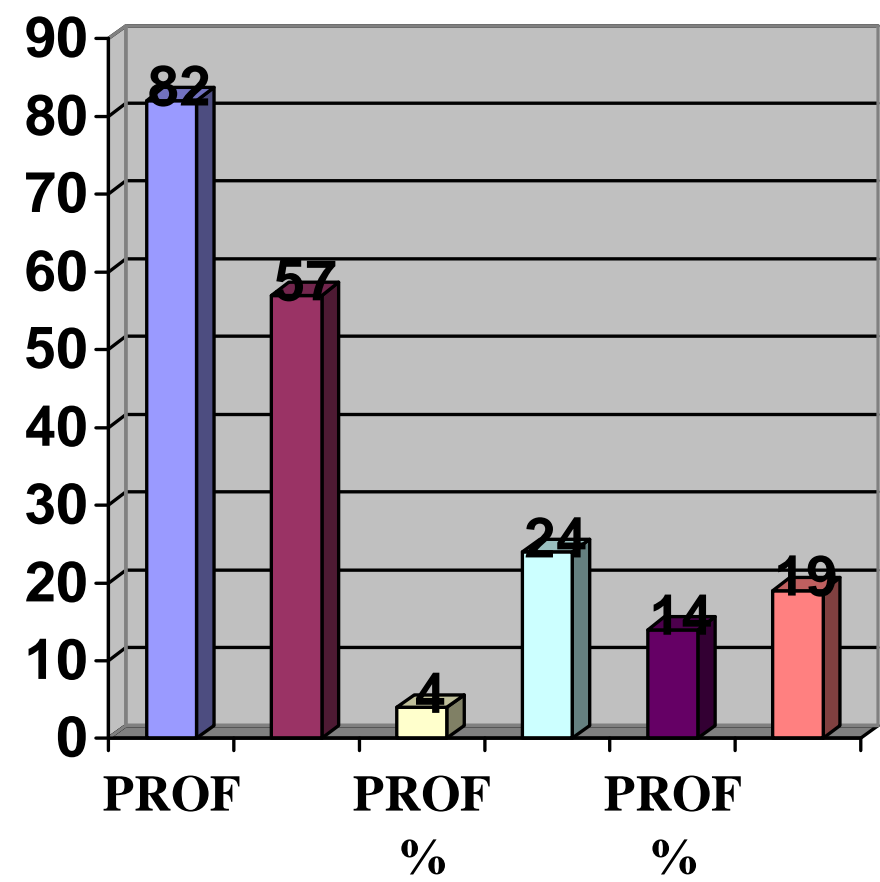

$\square$ PROF
$\square$ ESTUD \%
$\square$ PROF \%
$\square$ ESTUD \%
$\square$ PROF \%
$\square$ ESTUD \%

Figura 4. Comportamiento del conocimiento de los estudiantes (II)

Fuente: Elaboración propia (2010) 
En el complejo mundo discursivo, para plantear el análisis del contenido del texto, Van Dijk (1998) proporciona una aproximación analítica a partir del conjunto del texto; en vez de partir de la oración y sus componentes, parte de la hipótesis de unidades superiores de contenido a las cuales llama macroestructuras. Un modo de identificar la coherencia en su macroestructura (contenido del texto) radica en considerarla como una reconstrucción realizada por la persona que interpreta (los estudiantes).Para explicarla, este autor recurre al modelo usual de la lógica proposicional utilizado en la semántica.

\subsection{Dimensión elementos no verbales y paraverbales de los actos del habla}

El análisis de esta dimensión, correspondió a dialogo con los estudiantes sobre observaciones a sus profesores, tomando en cuenta que la modalidad oral o actos del habla son consustanciales al ser humano constitutiva de la persona como miembro de una especie, se produce en y con el cuerpo, aprovechando órganos del sistema respiratorio de diferentes partes de la cabeza: labios, lengua, fosas nasales; asimismo movimientos de los ojos, expresiones faciales, corporales, los cuales forman parte de la oralidad, así como las vocalizaciones y otros ruidos emitidos al hablar.

Es evidente, que la posibilidad de poder analizar la realidad de los encuentros interactivos entre los profesores y los estudiantes, incurrieron en el análisis del discurso y de la comunicación interpersonal, sin ver una triple realidad del lenguaje hablado, que sólo existió como un continuo verbal paralingüístico-kinésico, formado por sonidos y silencios; movimientos y posiciones estáticas, es decir, triple estructura básica de la comunicación tal como lo refiere Poyatos (1994, p.130).

En este marco referencial, se interpretan las respuestas de los estudiantes como positivas, ya que al preguntarles si el profesor mira a los alumnos al hablar, un $90 \%$ respondió estar de acuerdo, $8 \%$ indiferente y un $2 \%$ en desacuerdo. También se le preguntó a los alumnos si el profesor se burla de ellos cuando se equivocan y respondieron estar en desacuerdo un $77 \%$, un $13 \%$ indiferente y solo un $10 \%$ estar de acuerdo.

Cabe considerar, en las respuestas de los alumnos lo planteado por Van Dijk (1997) quien expone que la articulación, la recepción auditiva o los fonemas pueden ser marginales para un típico analista del discurso que prefiere mirar las estructuras más allá de las palabras, frases u oraciones. Sin embargo el tono de la voz, el volumen y la entonación son una rica fuente de variaciones por las cuales, se puede controlar el énfasis, la prominencia o la característica distintiva de la opinión, la emoción y la posición social (p. 255).

Al preguntarle al estudiante sobre la base planteada por este autor, en una afirmación formulada sobre sí la calidad de la voz del profesor era adecuada, un $72 \%$ respondió estar de acuerdo, un $21 \%$ indiferente y $7 \%$ en desacuerdo, cuestión que lleva a la investigadora a pensar que el discurso del profesor en el contexto cognitivo de los estudiantes es adecuado en referencia a la calidad y timbre de su voz. 
Sobre este aspecto, los estudiantes dijeron estar de acuerdo en un $76 \%$ que el no carraspea con frecuencia, no tose cuando está dando la clase, no utiliza onomatopeyas en el acto comunicativo, no emite ruidos de relleno que tiendan a confundir el mensaje del discurso y por supuesto, no existen las conductas frías que plantean Calsamiglia y Tuson (2001).

Estas autoras, al referirse a la proxémica consideran que esta es básicamente la manera en que el espacio se concibe individual y socialmente, a cómo los participantes se apropian del lugar donde se desarrolla un intercambio comunicativo y a cómo se distribuyen (p. 49). Asimismo, la calidad de la voz, se puede modular para conseguir efectos o manifestar intenciones deseadas. Así, un mensaje puede ser susurrado, dicho con ironía, seriedad o broma.

\section{CONCLUSIONES}

Los resultados invitan a reflexionar sobre el discurso del profesor donde el significado del texto ocupa el lugar central en el contexto cognitivo de los estudiantes durante el desarrollo de los eventos comunicativos en el salón de clases, por ello, la hermenéutica da cuenta de la organización del texto en el discurso, permitiendo su interpretación, comprensión y explicación, habida cuenta de su significado semántico y pragmático.

Se concluye que mas de la mitad de los estudiantes, de Comunicación Social consideran que el profesor no utiliza un lenguaje explícito, ni comparten con los alumnos el conocimiento del contenido programático, no comparte las experiencias de los profesores para emitir sus mensajes, no posee los recursos para emitir mensajes de diferente manera, los cálculos erróneos de los alumnos no son atendidos por los profesores, los estudiantes desconocen las intenciones del profesor durante las clases presenciales, antes de iniciar el proceso de comunicación los profesores no captan la atención del alumno, están de acuerdo que los múltiples significados del lenguaje utilizados por los profesores interfieren en la comprensión durante los encuentros pedagógicos; el 26\% se mostró indiferente y el 20\% estuvo en desacuerdo.

La investigación se centró, fundamentalmente, en el estudio de los procesos inferenciales situados, los profesores en este caso, activan para entender los enunciados, a partir de formas que parecen transgredir los principios racionales y los alumnos respetan para poder cooperar y comprender con relativa facilidad y agilidad.

En efecto los elementos no verbales y paraverbales de los actos del habla, el interés se centró en los gestos y posturas en la expresión de actitudes lingüísticas de los profesores ante la realidad comunicativa en el salón de clases, ello sirvió para mostrar la posición adoptada por los docentes frente a lo que dicen y hacen con los alumnos de la Escuela Comunicación Social, Universidad Dr. Rafael Belloso Chacín. 


\section{REFERENCIAS}

Beaugrande, R. \& Dressler, W. (1997). Introducción a la lingüística del texto. Barcelona: Ariel.

Calsamiglia, H. (1997). El estudio del discurso oral. Signos, teoría y práctica de la educación. Barcelona: Universidad Autónoma de Barcelona.

Calsamiglia, H. \& Tusón, A. (2001). Las cosas del decir. Barcelona: Ariel.

Chela-Flores, B. y otros (2001). Habla pública: de lo pragmático a lo fónico. Caracas: Fondo Editorial Tropykos.

Escandell, M. (1993). Introducción a la pragmática. Barcelona: Ariel.

Fairclough, N \& Wodak, R. (1997). Critical Discourse. Analysis. Londres: Sin editorial.

Flórez, R. (1999). Evaluación pedagógica y cognición. Bogotá: Mc Graw Hill.

Fullat, O. (1996). Filosofía de la educación. Barcelona: Ariel.

Gómez, C. (2002). Lenguaje y comunicación. Caracas: Panapo Venezuela.

Grice, P. (1995). Lógica y conversación. Madrid: Tecnos.

Habermas, J. (1990). Teoría de la acción comunicativa. Complementos y estudios previos. Madrid: Cátedra.

Knapp, M. (1995). La Comunicación no verbal. El Cuerpo y el Entorno. Barcelona: Paidós.

Martínez, M. (1994). Instrumentos de análisis del discurso escrito. Colombia: Universidad del Valle.

Poyatos, F. (1994). La comunicación no verbal I. Cultura, Lenguaje y Conversación. Madrid: Istmo.

Sperber, D. \& Wilson, D. (1995). Sobre la definición de relevancia. Madrid: Visor.

Tusón, A. \& Unamuno, V. (1999), ¿De qué estamos hablando? El mal-entendido en el discurso escolar. Discurso y Sociedad. Barcelona: Ediciones Positivas.

Van Dijk, T. C. (1998). Texto y contexto. Semántica y Pragmática del discurso. Madrid: Artes Gráficas. Tercera Edición.

Van Dijk, T. C. (1999). Ideología. Una aproximación multidisciplinaría. Barcelona: Gedisa. 


\section{María Guanipa-Pérez}

Postdoctorado en Gerencia de las Organizaciones (URBE). Dra. En Ciencias de la Educación (URBE). Magíster en Ciencias de la Educación área Planificación y Administración Educativa (LUZ). Lcda. Ciencias Pedagógicas área Tecnología Instruccional (LUZ). Maestra Normalista (Normal Alejandro Fuenmayor). Psicopedagoga Terapeuta. Directora del Centro de Investigación de Humanidades y Educación CIHE. Directora - Editora de la Revista Electrónica de Humanidades, Educación y Comunicación Social. REDHECS. Diseñadora de Programas de Postgrado a Distancia. Coordinadora del Postgrado a Distancia: Especialización Docencia para la Educación Básica. Universidad Rafael Belloso Chacín. Miembro del Programa de Promoción a la Investigación (PEI Nivel B) 